\title{
Influence of Galactic Cosmic Rays on atmospheric composition and dynamics
}

\author{
M. Calisto ${ }^{1}$, I. Usoskin ${ }^{2}$, E. Rozanov ${ }^{1,3}$, and T. Peter ${ }^{1}$ \\ ${ }^{1}$ Institute for Atmospheric and Climate Science ETH, Zurich, Switzerland \\ ${ }^{2}$ Sodankylä Geophysical Observatory, University of Oulu, 90014 Oulu, Finland \\ ${ }^{3}$ Physical-Meteorological Observatory/World Radiation Center, Davos, Switzerland
}

Received: 26 November 2010 - Published in Atmos. Chem. Phys. Discuss.: 10 January 2011

Revised: 25 April 2011 - Accepted: 27 April 2011 - Published: 13 May 2011

\begin{abstract}
This study investigates the influence of the Galactic Cosmic Rays (GCRs) on the atmospheric composition, temperature and dynamics by means of the 3-D Chemistry Climate Model (CCM) SOCOL v2.0. Ionization rates were parameterized according to CRAC:CRII (Cosmic Ray induced Cascade: Application for Cosmic Ray Induced Ionization), a detailed state-of-the-art model describing the effects of GCRs in the entire altitude range of the CCM from $0-80 \mathrm{~km}$. We find statistically significant effects of GCRs on tropospheric and stratospheric $\mathrm{NO}_{\mathrm{x}}, \mathrm{HO}_{\mathrm{x}}$, ozone, temperature and zonal wind, whereas $\mathrm{NO}_{\mathrm{x}}, \mathrm{HO}_{\mathrm{x}}$ and ozone are annually averaged and the temperature and the zonal wind are monthly averaged. In the Southern Hemisphere, the model suggests the GCR-induced $\mathrm{NO}_{\mathrm{x}}$ increase to exceed $10 \%$ in the tropopause region (peaking with $20 \%$ at the pole), whereas $\mathrm{HO}_{\mathrm{x}}$ is showing a decrease of about $3 \%$ caused by enhanced conversion into $\mathrm{HNO}_{3}$. As a consequence, ozone is increasing by up to $3 \%$ in the relatively unpolluted southern troposphere, where its production is sensitive to additional $\mathrm{NO}_{\mathrm{x}}$ from GCRs. Conversely, in the northern polar lower stratosphere, GCRs are found to decrease $\mathrm{O}_{3}$ by up to $3 \%$, caused by the additional heterogeneous chlorine activation via $\mathrm{ClONO}_{2}+\mathrm{HCl}$ following GCR-induced production of $\mathrm{ClONO}_{2}$. There is an apparent GCR-induced acceleration of the zonal wind of up to $5 \mathrm{~m} \mathrm{~s}^{-1}$ in the Northern Hemisphere below $40 \mathrm{~km}$ in February, and a deceleration at higher altitudes with peak values of $3 \mathrm{~m} \mathrm{~s}^{-1}$ around $70 \mathrm{~km}$ altitude. The model also indentifies GCR-induced changes in the surface air, with warming in the eastern part of Europe and in Russia (up to $2.25 \mathrm{~K}$ for March values) and cooling in Siberia
\end{abstract}

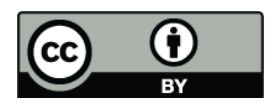

Correspondence to: $\mathrm{M}$. Calisto (marco.calisto@env.ethz.ch) and Greenland (by almost $2 \mathrm{~K}$ ). We show that these surface temperature changes develop even when the GCR-induced ionization is taken into account only above $18 \mathrm{~km}$, suggesting that the stratospherically driven strengthening of the polar night jet extends all the way down to the Earth's surface.

\section{Introduction}

Galactic cosmic rays (GCRs) are energetic particles (mostly protons and $\alpha$-particles) which originate from outside of the solar system. While their flux outside the solar system can be regarded as roughly isotropic and time independent, at least on the time scales studied here (Usoskin et al., 2004), the intensity of GCRs near the Earth varies as a result of the modulation inside the heliosphere, i.e. the spatial region of about 200 Earth-Sun distances controlled by the solar wind and the solar magnetic field. Variations of the cosmic ray flux depend also on particle energy: the flux of less energetic $(<1 \mathrm{GeV})$ particles varies by an order of magnitude modulated by the solar cycle, while energetic GCRs (above $100 \mathrm{GeV}$ ) are hardly modulated (Bazilevskaya et al., 2008).

When galactic cosmic rays enter the Earth's atmosphere they collide with the ambient atmospheric gas molecules, thereby ionizing them. In this process they may produce secondary particles, which can be sufficiently energetic to contribute themselves to further ionization of the neutral gases. This leads to the development of an ionization cascade (or shower). The intensity and penetration depth of the cascade depends on the energy of the primary cosmic particles. Cascades of particles with several hundred $\mathrm{MeV}$ of kinetic energy may reach the ground. However, due to their charge cosmic ray particles are additionally deflected by the geomagnetic field. Almost all particles can penetrate into the

Published by Copernicus Publications on behalf of the European Geosciences Union. 

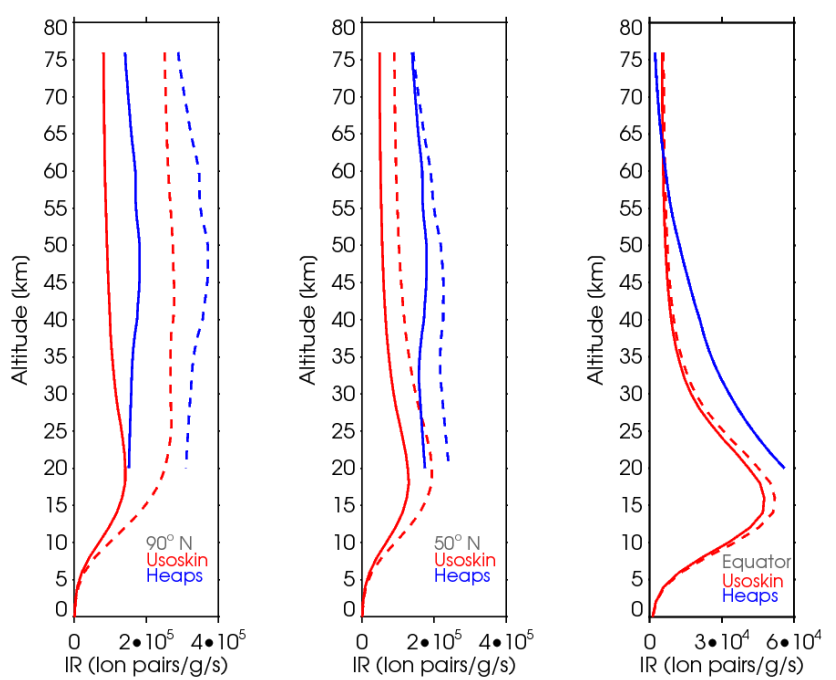

Fig. 1. Red lines: ionization rates (number of ion pairs produced per air mass and time unit) for several geomagnetic latitudes as computed by the CRAC:CRII model (Usoskin, Kovaltsov and Mironova, 2010). Blue lines: ionization rate computed by Heaps, (1978). Solid lines: ionization rate during solar maximum. Dashed lines: ionization rate during solar minimum. Note different scales on abscissas in dependence on geomagnetic latitude.

polar regions, where the magnetic field lines are perpendicular to the ground, whereas only the rare most highly energetic particles with energies above $15 \mathrm{GeV}$ are able to penetrate the lower atmosphere near the equator.

Early models of the cosmic ray induced ionization (CRII) were (semi)empirical (e.g., O’Brien, 1970; Heaps, 1978) or simplified analytical (Vitt and Jackman, 1996; O'Brien, 2005). Nicolet (1975), however, has used data from balloon soundings and ionization chambers to deduce the production rates of nitric oxide in the auroral region. State-of-the-art models (Usoskin et al., 2004; Desorgher et al., 2005; Usoskin and Kovaltsov, 2006) are based on Monte-Carlo simulations of the atmospheric cascade and can provide 3-D time dependent computations of the CRII.

Between the surface and $25-30 \mathrm{~km}$ CRII is the main source of the atmospheric ionization (Bazilevskaya et al. 2008) with the maximum ionization rate caused by the Bragg peak in the stopping power around $15 \mathrm{~km}$ (Pfotzer maximum), which is clearly visible in Fig. 1 based on the Usoskin et al. (2010) parameterization (red lines). The ionization rates calculated by means of the parameterization of Heaps (1978), represented by blue lines in Fig. 1, are still used often in modeling work (e.g., Schmidt et al., 2006). However, this parameterization does not reflect the Pfotzer maximum, because it does not cover the range from $0-18 \mathrm{~km}$.

The CRII leads to the production of odd nitrogen. For example, fast secondary electrons $\left(\mathrm{e}^{*}\right)$ can dissociate the nitrogen molecule, $\mathrm{N}_{2}+\mathrm{e}^{*} \rightarrow 2 \mathrm{~N}\left({ }^{2} \mathrm{D}\right)+\mathrm{e}$, and almost all of the $\mathrm{N}$ atoms in the excited ${ }^{2} \mathrm{D}$ state react with $\mathrm{O}_{2}$, producing nitric oxide, $\mathrm{N}\left({ }^{2} \mathrm{D}\right)+\mathrm{O}_{2} \rightarrow \mathrm{NO}+\mathrm{O}$. Vitt and Jackman (1996) estimated CRII to produce 3.0 to $3.7 \times 10^{33}$ molecules of odd nitrogen per year in the global stratosphere, which amounts to about $10 \%$ of the $\mathrm{NO}_{x}$ production following $\mathrm{N}_{2} \mathrm{O}$ oxidation. They also mention that the northern polar/subpolar stratosphere $\left(>50^{\circ} \mathrm{N}\right)$ is believed to be supplied with $\mathrm{NO}_{\mathrm{x}}$ in equal amounts by GCRs ( 7.1 to $9.6 \times 10^{32}$ molecules $\mathrm{yr}^{-1}$ ) and by $\mathrm{N}_{2} \mathrm{O}$ oxidation $\left(9.4\right.$ to $10.7 \times 10^{32}$ molecules $\mathrm{yr}^{-1}$ ). In the deep polar winter stratosphere, when air masses experience sunlit periods only infrequently and photolysis of $\mathrm{HNO}_{3}$ becomes negligible, CRII constitutes an important source of $\mathrm{NO}_{\mathrm{x}}$ in high latitudes, competing with rapid downwardtransport of odd nitrogen from the mesosphere or lower thermosphere into the stratosphere, as it occurs in many winters (e.g. Seppälä et al., 2007).

Below the mesopause, where water cluster ions can form, CRII contributes to the formation of $\mathrm{HO}_{x}$ radicals. For example, molecular oxygen ions $\left(\mathrm{O}_{2}^{+}\right)$produced by GCRs can via attachment of molecular oxygen form $\mathrm{O}_{4}^{+}$, which reacts with water: $\mathrm{O}_{4}^{+}+\mathrm{H}_{2} \mathrm{O} \rightarrow \mathrm{O}_{2}^{+} \cdot \mathrm{H}_{2} \mathrm{O}+\mathrm{O}_{2}$. This hydrated ion quickly hydrates further to produce $\mathrm{OH}: \mathrm{O}_{2}^{+} \cdot \mathrm{H}_{2} \mathrm{O}$ $+\mathrm{H}_{2} \mathrm{O} \rightarrow \mathrm{H}_{3} \mathrm{O}^{+} \mathrm{OH}+\mathrm{O}_{2} \rightarrow \mathrm{H}_{3} \mathrm{O}^{+}+\mathrm{OH}+\mathrm{O}_{2}$ (Aikin, 1994). GCR-driven $\mathrm{HO}_{\mathrm{x}}$ production competes with the most important source for $\mathrm{HO}_{\mathrm{x}}$ in the atmosphere, the photolytically driven oxidation of water vapor $\left(\mathrm{H}_{2} \mathrm{O}\right)$ by excited oxygen atoms, $\mathrm{O}\left({ }^{1} \mathrm{D}\right)$, which are themselves produced from ozone photolysis. However, during polar night, $\mathrm{HO}_{\mathrm{x}}$ is mainly produced by the GCRs given that no UV radiation is available for $\mathrm{O}\left({ }^{1} \mathrm{D}\right)$ production.

The influence of GCRs on atmospheric chemistry has been studied by Krivolutsky et al. (2002) with a 1-D photochemical model. They found that ozone at $50^{\circ}$ geomagnetic latitude might indeed be sensitive to the additional $\mathrm{NO}_{\mathrm{x}}$ source. Their 1-D model predicted maximum GCRinduced increases in $\mathrm{NO}_{\mathrm{x}}$ of $4.5 \%$ around $10 \mathrm{~km}$, enhancing tropospheric ozone by $0.6 \%$, whereas above about $18 \mathrm{~km}$ ozone decreases with a maximum reduction of $0.5 \%$ close to $20 \mathrm{~km}$. Above $35 \mathrm{~km}$ altitude they found no influence caused by the GCRs. The evaluation of the impact of GCRs on atmospheric temperature and dynamics, which adds to the chemical changes, cannot be performed with an 1-D model but requires the use of a 3-D chemistry-climate model (CCM) that is capable of describing the coupling between physicochemical processes and large-scale dynamics.

Here we study the effect of CRII using the recently developed CRAC:CRII (Cosmic Ray induced Cascade: Application for Cosmic Ray Induced Ionization) model, and then use the results of this event-based local model to force the global CCM SOCOL, focusing on the impact of CRII-induced $\mathrm{NO}_{\mathrm{x}}$ and $\mathrm{HO}_{\mathrm{x}}$ on chemistry, temperature and dynamics from the ground to $0.01 \mathrm{hPa}$ barometric pressure (altitude of $\sim 80 \mathrm{~km}$ ).

We have also addressed the difference between the stateof-the-art parameterization of the ionization rate by Usoskin et al. (2010) and the more traditional parameterization given 
by Heaps (1978), which was based on fitting results from sealed ionization chambers flown continuously (yearly) on balloons extending to heights of $35 \mathrm{~km}$. The parameterization by Heaps (1978) was and is widely used in various models (Verronen et al., 2002; Schmidt et al., 2006; Winkler et al., 2009).

Many studies of atmospheric chemistry and dynamics omit the influence of GCRs altogether, as was done for example in the first Chemistry-Climate Model Validation Activity (CCMVal) for coupled CCMs (Eyring et al., 2006) and in the most recent CCMVal report (see the homepage of SPARC: http://www.atmosp.physics.utoronto.ca/SPARC/ ccmval_final/index.php). Here, we use the CCM SOCOL, which is one of the CCMs that participated in the CCMVal activity, to investigate the consequences of this omission.

The models and experimental setup are described in Sect. 2, the results containing the GCR effects on several chemical species and the comparison between the parameterizations by Usoskin et al. (2010) and Heaps (1978) are presented in Sect. 3. In Sect. 4 we give a short summary of the results.

\section{Description of the model and experimental setup}

\subsection{Chemistry-climate modeling with SOCOL}

The CCM SOCOL represents a combination of the global circulation model MA-ECHAM4 and the chemistrytransport model MEZON. MA-ECHAM4 (Manzini et al., 1997) is a spectral model with T30 horizontal truncation resulting in a grid spacing of about $3.75^{\circ}$; in the vertical direction the model has 39 levels in a hybrid sigma-pressure coordinate system spanning the model atmosphere from the surface to $0.01 \mathrm{hPa}$.

The chemical-transport part MEZON (Rozanov et al., 1999; Egorova et al., 2003) has the same vertical and horizontal resolution and treats 41 chemical species of the oxygen, hydrogen, nitrogen, carbon, chlorine and bromine groups, which are coupled by 140 gas-phase reactions, 46 photolysis reactions and 16 heterogeneous reactions in/on aqueous sulfuric acid aerosols, water ice and nitric acid trihydrate (NAT). The original version of the CCM SOCOL was described by Egorova et al. (2005).

Mixing ratios as a function of time of long lived wellmixed gases (e.g. $\mathrm{N}_{2} \mathrm{O}, \mathrm{CH}_{4}$, ODS) were prescribed in the planetary boundary layer with no spatial dependency, while the fluxes of $\mathrm{NO}_{\mathrm{x}}$ and $\mathrm{CO}$ were prescribed using emission data sets. The time dependent solar irradiance was also taken into account. The sea surface temperatures and sea ice distributions were prescribed from observational data. All applied boundary conditions except GCRs are identical to the REFB1 run described by Morgenstern et al. (2010).
An extensive evaluation of the CCM SOCOL (Egorova et al., 2005; Eyring et al., 2006, 2007) revealed model deficiencies in the chemical-transport part and led to the development of the CCM SOCOL v2.0 (which is applied in this study). The new features of the SOCOLv2.0 are: (i) all species are transported separately; (ii) the mass fixer correction after each semi-Lagrangian transport step is calculated for the chlorine, bromine and nitrogen families instead for individual family members, but then applied to each individual species; (iii) the mass fixer is applied to ozone only over the latitude band $40^{\circ} \mathrm{S}-40^{\circ} \mathrm{N}$ to avoid artificial mass loss in the polar areas; (iv) the water vapor removal by the highest ice clouds (between $100 \mathrm{hPa}$ and the tropical cold point tropopause) is explicitly taken into account to prevent an overestimation of stratospheric water content; (v) the list of ozone-depleting substances is extended to 15 for the chemical treatment, while for the transport they are still clustered into three tracer groups; (vi) the heterogeneous chemistry module was updated to include $\mathrm{HNO}_{3}$ uptake by aqueous sulfuric acid aerosols, a parameterization of the liquid-phase reactive uptake coefficients and the NAT particle number densities are limited by an upper boundary of $5 \times 10^{-4} \mathrm{~cm}^{-3}$ to take account of the fact that observed NAT clouds are often strongly supersaturated. A comprehensive description and evaluation of the CCM SOCOL v2.0 is presented by Schraner et al. (2008).

\subsection{Cosmic Ray Induced Ionization modeling}

Here we study the effect of CRII using the recently developed CRAC:CRII model (see Usoskin et al., 2004; Usoskin and Kovaltsov, 2006), which has been extended from the stratosphere (Usoskin and Kovaltsov, 2006) to the upper atmosphere (Usoskin et al., 2010). The model is based on a Monte-Carlo simulation of the atmospheric cascade and reproduces the observed data within $10 \%$ accuracy in the troposphere and lower stratosphere (Bazilevskaya et al., 2008; Usoskin et al., 2009). Usoskin's parameterization works well in the lower part below $30 \mathrm{~km}$, where GCRs are the main source of ionization. The CRAC:CRII model has been verified by comparison with available direct data sets and other models (e.g., Bazilevskaya et al., 2008; Usoskin et al., 2009). It does, however, underestimate the ionization above $\sim 30 \mathrm{~km}$ since it neglects other non-GCR sources of ionization, UVI and precipitating particles (higher up in the polar atmosphere). On the other hand, Heaps' parameterization is based on scarce empirical data and may contain large uncertainties. It appears to be closer to the data in the upper polar atmosphere. As a summary, we believe that Usoskin's model produces more realistic results below $30 \mathrm{~km}$, but is prone to underestimating ionization above that altitude. The results of the CRAC:CRII model are parameterized to give ion pair production rate as a function of the altitude (quantified via the barometric pressure), geomagnetic latitude (quantified via geomagnetic cutoff rigidity) and solar activity (quantified 
via the modulation potential $\Phi$ ), see Usoskin et al. (2005). In Fig. 1 we show the ionization rates for several geomagnetic latitudes as computed by the CRAC:CRII model (red line), compared to the ionization rates computed by the parameterization of Heaps (1978) (blue line). Solid lines show the ionization rates during solar minimum, the dashed lines during solar maximum.

This parameterization of the ionization rates cannot be directly used in CCM SOCOL, which has no explicit treatment of ion chemistry and requires the conversion of the ionization rates into $\mathrm{NO}_{\mathrm{x}}$ and $\mathrm{HO}_{\mathrm{x}}$ production rates. Following Porter et al. (1976), we assumed that $1.25 \mathrm{NO}_{\mathrm{x}}$ molecules are produced per ion pair, and $45 \%$ of this $\mathrm{NO}_{\mathrm{x}}$ production is assumed to yield ground state atomic nitrogen $\mathrm{N}\left({ }^{4} \mathrm{~S}\right)$, whereas $55 \%$ yields the electronically excited state atomic nitrogen $\mathrm{N}\left({ }^{2} \mathrm{D}\right)$. While the ground state may lower the overall $\mathrm{NO}_{\mathrm{x}}$ concentration via $\mathrm{N}\left({ }^{4} \mathrm{~S}\right)+\mathrm{NO} \rightarrow \mathrm{N}_{2}+\mathrm{O}, \mathrm{N}\left({ }^{2} \mathrm{D}\right)$ converts instantaneously to $\mathrm{NO}$ (see Introduction).

The production of $\mathrm{HO}_{\mathrm{x}}$ has been studied by Solomon and Crutzen (1981) with a 1-D time-dependent model of neutral and ion chemistry. They parameterized the number of odd hydrogen particles produced per ion pair as a function of altitude and ionization for daytime, polar summer conditions of temperature, air density and solar zenith angle. We implement their parameterization in the CCM SOCOL to take into account the GCR induced production of $\mathrm{HO}_{\mathrm{x}}$ from the ground up to the height of $0.01 \mathrm{hPa}$ barometric pressure (altitude of $\sim 80 \mathrm{~km}$ ).

For this study, we have carried out three 27-year long runs of CCM SOCOL v2.0 from 1976 to 2002 considering the solar cycle dependency and applying the actually observed variations in the cosmic ray flux. The control run has been performed without the influence of the galactic cosmic rays, while two experiment runs include GCRs using the ionization rates given by Usoskin et al. (2010) and Heaps (1978). Our model is driven by time varying boundary conditions for the source gases, aerosol loading, solar irradiance and sea surface temperatures. All resulting changes in the atmospheric state are taken into account for the calculation of statistical significance. The computed statistical significance would probably be higher if boundary conditions were held fixed, because the variability around the mean state is smaller in the absence of changes in the prescribed fields. The first two years of the runs have been omitted from the analysis to eliminate possible spin up problems of the model. In this paper we analyze only the difference between two runs (with and without GCRs) to establish the upper limit of the potential effects. The analysis of the difference between solar max and solar min is more complicated because the extraction of the GCR related signal would require time dependent statistical analysis (e.g. multiple regression analysis), which is difficult for our rather short time series. In a final section we compare the results with runs using the often applied CRII parameterization of Heaps (1978).

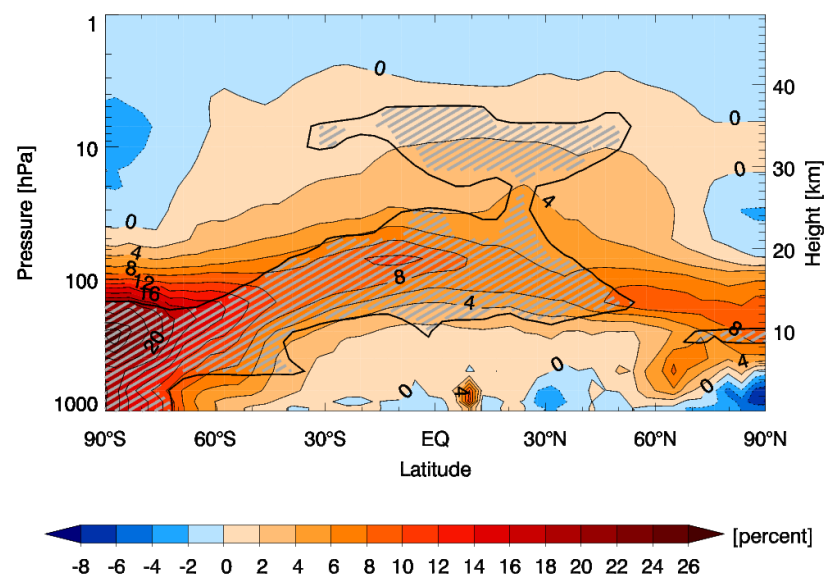

Fig. 2. Annual mean effect of GCRs on zonal mean $\mathrm{NO}_{\mathrm{x}}$, $\left(\left[\mathrm{NO}_{\mathrm{x}}\right]_{\mathrm{GCR}}-\left[\mathrm{NO}_{\mathrm{X}}\right]_{\text {control }}\right) /\left[\mathrm{NO}_{\mathrm{X}}\right]_{\text {control }}$, in percent $\left(\left[\mathrm{NO}_{\mathrm{X}}\right]=[\mathrm{NO}]\right.$ $+\left[\mathrm{NO}_{2}\right]$ ). Results are averaged from 1978-2002 (after allowing for a 2-year model spin-up) with appropriate accounting for solar minimum and maximum periods. Solid contours indicate positive, dotted contours negative changes. Hatched areas (enclosed by solid contours) indicate changes with at least $95 \%$ statistical significance.

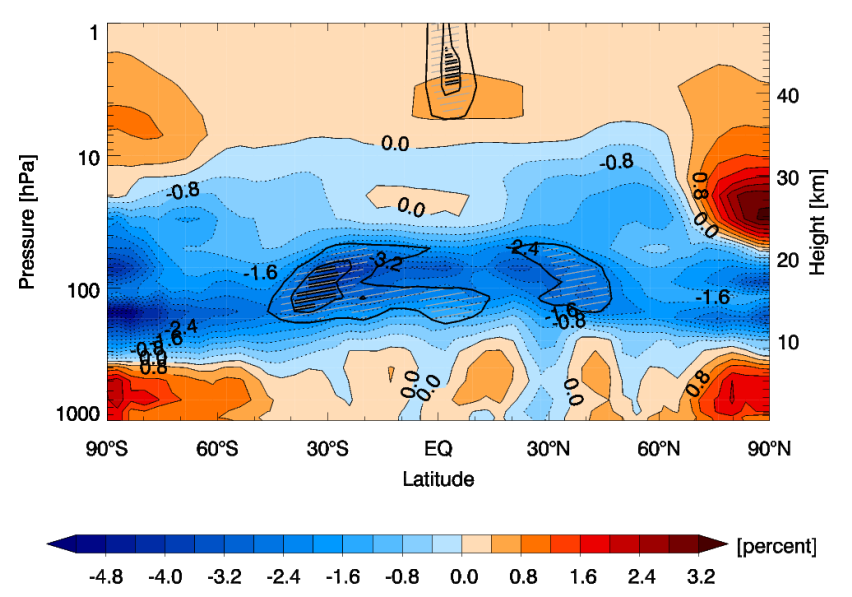

Fig. 3. Annual mean effect of GCRs on zonal mean $\mathrm{HO}_{\mathrm{x}}$, $\left(\left[\mathrm{HO}_{\mathrm{x}}\right]_{\mathrm{GCR}^{-}}\left[\mathrm{HO}_{\mathrm{x}}\right]_{\text {control }}\right) /\left[\mathrm{HO}_{\mathrm{x}}\right]_{\text {control }}$, in percent $\left(\left[\mathrm{HO}_{\mathrm{x}}\right]=[\mathrm{H}]+\right.$ $[\mathrm{OH}]+\left[\mathrm{HO}_{2}\right]$ ). Results are averaged from 1978-2002 (after allowing for a 2-year model spin-up) with appropriate accounting for solar minimum and maximum periods. Hatched areas (enclosed by solid contours) indicate statistically significant changes with at least $95 \%$ (inner contours) or $80 \%$ (outer contours).

\section{Results}

Figures 2-5 show the annual mean response of the zonal mean $\mathrm{NO}_{\mathrm{x}}, \mathrm{HO}_{\mathrm{x}}, \mathrm{HNO}_{3}$ and ozone to the GCRs calculated as a relative deviation of the experiment run from the reference run. The figures are limited to the range from $1000 \mathrm{hPa}$ to $1 \mathrm{hPa}$ even though the model reaches up to $0.01 \mathrm{hPa}$, because there is little influence of the GCRs above $1 \mathrm{hPa}$. 


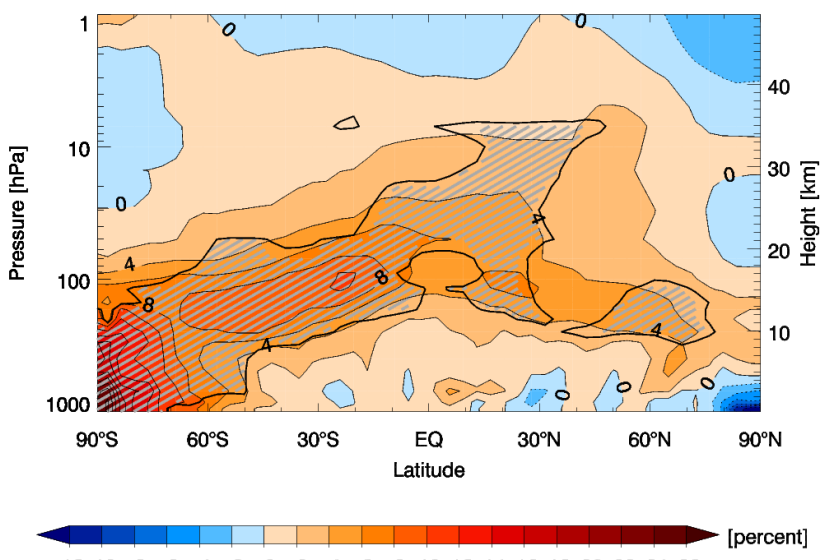

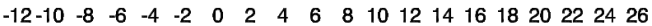

Fig. 4. Annual mean effect of GCRs on zonal mean $\mathrm{HNO}_{3}$, $\left(\left[\mathrm{HNO}_{3}\right]_{\mathrm{GCR}}-\left[\mathrm{HNO}_{3}\right]_{\text {control }}\right) /\left[\mathrm{HNO}_{3}\right]_{\text {control }}$, in percent. Results are averaged from 1978-2002 (after allowing for a 2-year model spin-up) with appropriate accounting for solar minimum and maximum periods. Hatched areas (enclosed by thick solid contours) indicate changes with at least $95 \%$ statistical significance.

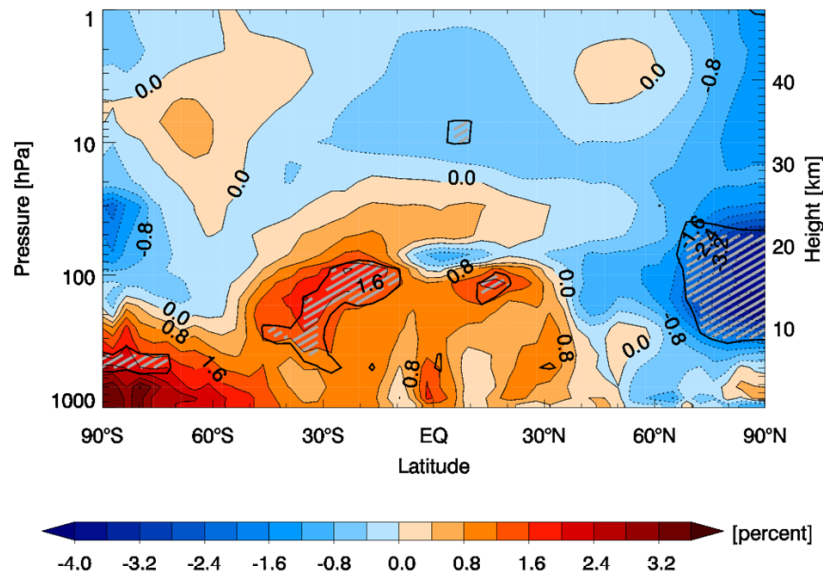

Fig. 5. Annual mean effect of GCRs on zonal mean ozone, $\left(\left[\mathrm{O}_{3}\right]_{\mathrm{GCR}}-\left[\mathrm{O}_{3}\right]_{\text {control }}\right) /\left[\mathrm{O}_{3}\right]_{\text {control }}$, given in percent. Results are averaged from 1978-2002 (after allowing for a 2-year model spin-up) with appropriate accounting for solar minimum and maximum periods. Hatched areas (enclosed by thick solid contours) indicate changes with at least $95 \%$ statistical significance.

\subsection{Chemical species}

\subsection{1 $\mathrm{NO}_{\mathrm{x}}$}

The galactic cosmic rays produce substantial amounts of $\mathrm{NO}_{\mathrm{x}}$ during all seasons (not shown). In the annual mean the simulated $\mathrm{NO}_{x}$ increase affects most of the troposphere, exceeding $20 \%$ or $10 \mathrm{pptv}$ in the region extending from the south pole to $60^{\circ} \mathrm{N}$ around $8-12 \mathrm{~km}$ altitude (see Fig. 2, significant changes at $95 \%$ level are marked by hatching). There is also a significant impact on the tropical and sub- tropical middle stratosphere. The reason for smaller effects on the upper stratosphere lies in the vertical distribution of the ionization rates shown in Fig. 1: the ionization rate is the highest between 15 and $20 \mathrm{~km}$, rendering the production of odd nitrogen by GCRs highest. The difference in significance between the southern to northern hemispheric troposphere is explained by the fact that more $\mathrm{NO}_{\mathrm{x}}$ is produced anthropogenically in the Northern Hemisphere (NH) than in the Southern Hemisphere (SH), making the GCR-induced signal most relevant in the remote regions in the $\mathrm{SH}$.

The annual mean $\mathrm{NO}_{\mathrm{x}}$ production by GCRs in the southern hemispheric polar region (up to 5 pptv $\mathrm{NO}_{\mathrm{x}}$ in January south of $70^{\circ} \mathrm{S}$ ) is comparable to or even more important than the natural production through lightning (up to 2 pptv $\mathrm{NO}_{\mathrm{x}}$ in January south of $70^{\circ} \mathrm{S}$, Penner et al., 1998).

\subsection{2 $\mathrm{HO}_{\mathrm{x}}$ and $\mathrm{HNO}_{3}$}

Figure 3 represents the response of annual mean zonal mean $\mathrm{HO}_{\mathrm{x}}$ to GCRs. The $\mathrm{HO}_{\mathrm{x}}$ increase due to GCR-induced production is largely compensated or overcompensated by $\mathrm{NO}_{\mathrm{x}}$ production followed by $\mathrm{HO}_{\mathrm{x}}$ deactivation. Thus, there is no statistically significant $\mathrm{HO}_{\mathrm{x}}$ increase except in the upper tropical stratosphere, rather a broad area of significant GCRinduced $\mathrm{HO}_{\mathrm{x}}$ reduction in the tropical/mid-latitude UTLS. The inner hatched areas, representing $95 \%$ statistical significance, show a decrease of about $3 \%$ or 0.1 pptv over the southern hemispheric mid-latitudes at an altitude of $\sim 20 \mathrm{~km}$. The outer hatched areas, representing $80 \%$ significance, show a decrease of up to $3 \%$. This broad area of $\mathrm{HO}_{\mathrm{x}}$ decrease coincides with a region of the highest $\mathrm{NO}_{\mathrm{x}}$ enhancements and can be explained by the more intensive removal of $\mathrm{OH}$ via $\mathrm{OH}+\mathrm{NO}_{2}+\mathrm{M} \rightarrow \mathrm{HNO}_{3}+\mathrm{M}$, resulting in a significant $\mathrm{HNO}_{3}$ increase of about $8 \%$ (Fig. 4). The pattern and the magnitude of $\mathrm{HNO}_{3}$ increase seen in Fig. 4 are similar to the increase in $\mathrm{NO}_{\mathrm{x}}$ because our parameterization of the ionization effects on the chemical composition of the atmosphere describes only the direct production of $\mathrm{NO}_{\mathrm{x}}$ and $\mathrm{HO}_{\mathrm{x}}$ as a function of ionization rates (see Sect. 2). It means that the $\mathrm{HNO}_{3}$ build-up in our model directly results from the GCR induced $\mathrm{NO}_{\mathrm{x}}$ production. $\mathrm{HNO}_{3}$ production due to ion-ion recombination or positive hydrated ion reaction with $\mathrm{N}_{2} \mathrm{O}_{5}$ cannot be properly considered in the framework of our model, however it does not substantially limit the model capability, because $\mathrm{HNO}_{3}$ caused by these processes is important only above $10 \mathrm{hPa}$ where the ionization by GCRs is rather small (Kawa et al, 1995; Aikin et al, 1997).

\subsubsection{Ozone}

Significant increase of $\mathrm{NO}_{\mathrm{x}}$ in the southern hemispheric troposphere leads to the statistically significant ozone enhancement. As mentioned above ozone photochemistry in the southern hemispheric troposphere is in large parts $\mathrm{NO}_{\mathrm{x}}{ }^{-}$ limited, so that the CRII relaxes this limitation leading to up 
to $3 \%$ or 1 ppbv ozone increase (see Fig. 5). Conversely, in the northern polar lowermost stratosphere a significant ozone decrease of more than $3 \%$ is caused by the additional production of $\mathrm{ClONO}_{2}$ via $\mathrm{ClO}+\mathrm{NO}_{2}+\mathrm{M} \rightarrow \mathrm{ClONO}_{2}+\mathrm{M}$, which in a second step reacts in heterogeneous reactions on polar stratospheric cloud particles or cold sulfate aerosols to enhance chlorine activation, $\mathrm{ClONO}_{2}+\mathrm{HCl} \stackrel{\text { het }}{\rightarrow} \mathrm{Cl}_{2}+\mathrm{HNO}_{3}$ (with subsequent photolysis $\mathrm{Cl}_{2}+h v \rightarrow \mathrm{Cl}+\mathrm{Cl}$ ). As a secondary effect, higher $\mathrm{HNO}_{3}$ concentrations in the polar winter stratosphere lead to enhanced polar stratospheric cloud occurrences, and hence to faster heterogeneous chemical processing. The ozone decrease by the activated chlorine is negligible in the southern hemispheric polar region because the background concentration of chlorine is too high. The southern hemispheric polar region is closer to saturation (more available $\mathrm{Cl}_{\mathrm{y}}$ due to stronger downward transport in polar vortex, lower temperature, more PSC's, very low ozone), therefore no statistical significant ozone decrease caused by the GCRs is observed.

The latitudinal average of our results for $\mathrm{O}_{3}$ and $\mathrm{NO}_{\mathrm{x}}$ resemble the results of simple 1-D model calculations published by Krivolutsky et al. (2002). For ozone they modeled a maximum increase in the troposphere at a height of approximately $10 \mathrm{~km}$ and a maximum decrease at about $20 \mathrm{~km}$. For $\mathrm{NO}$ and $\mathrm{NO}_{2}$, their peak is visible at $10 \mathrm{~km}$. In their work the influence of the GCRs vanishes above $35 \mathrm{~km}$. The hemispheric asymmetries discussed above could, of course, not be retrieved in their 1-D calculation. Also, because Krivolutsky et al. (2002) did not discuss $\mathrm{HO}_{\mathrm{x}}$ in their paper, it is not possible to make a quantitative comparison with our results.

\subsection{Temperatures and winds}

The effects of GCRs on monthly mean ozone, temperatures and winds are noticeable year-round. However, significance is highest for winter/spring, hence results are displayed for this season in Fig. 6. The upper panel in Fig. 6 shows the monthly mean zonal mean changes for ozone during February. The significant area and the percentage of decrease are similar to the annual mean results shown in Fig 5. A decrease of up to $5 \%$ or more than $60 \mathrm{ppbv}$ is visible in the $\mathrm{NH}$ polar region between 20 and almost $30 \mathrm{~km}$. The influence of the GCRs on the SH is strongest in the troposphere, but remains statistically insignificant on the $95 \%$ level. As discussed above, the reason for the ozone depletion in the $\mathrm{NH}$ polar region is the additional GCR-induced chlorine activation.

\subsubsection{Temperature profile}

The center panel of Fig. 6 shows zonal mean response of the temperature in February. There is a cooling in the NH lowermost stratosphere (below $20 \mathrm{~km}$ altitude), resulting from the radiative cooling caused by the ozone loss. This cooling is facing a warming at low altitudes at about $40^{\circ} \mathrm{N}$. These two effects lead to an increase in the latitudinal temperature gra-

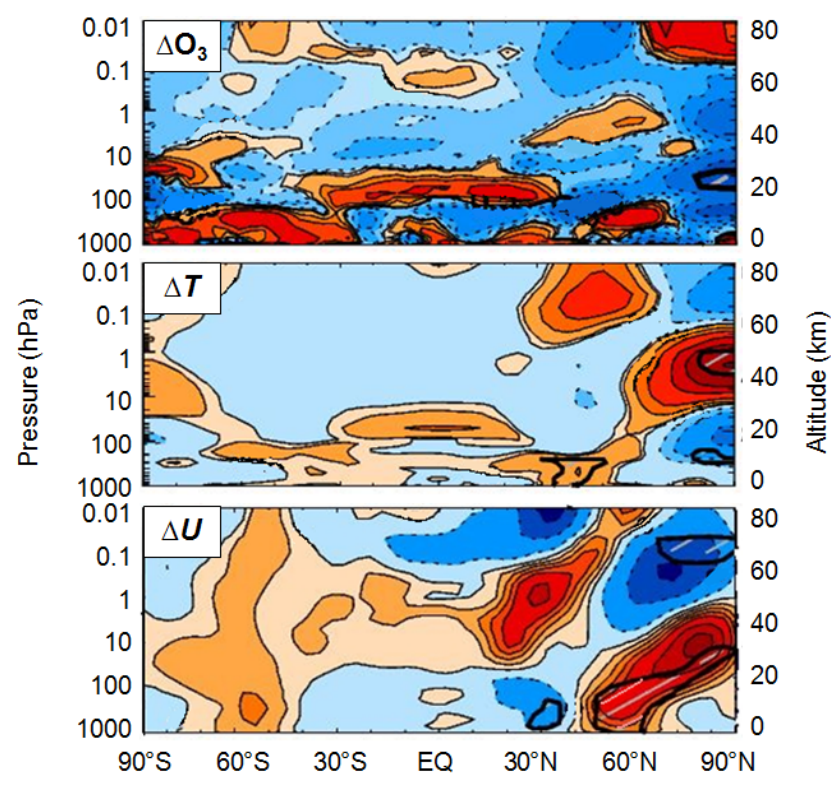

Fig. 6. Monthly mean zonal mean effects of GCRs on ozone $\left(\mathrm{O}_{3}\right)$, temperature $(T)$ and zonal wind $(U)$ for the month of February. Red colors: increases; blue colors: decreases. Upper panel: effect on $\mathrm{O}_{3}$ given in percent. Contour levels: $-5,-2,-1,-0.5,-0.1$, $0,0.1,0.5,1,2,5 \%$. Center panel: effect on $T$ given in Kelvin. Contour levels: $-5,-3,-2,-1,-0.5,-0.1,0,0.1,0.5,1,2,3,5$ K. Lower panel: effect on $U$ given in $\mathrm{m} \mathrm{s}^{-1}$. Contour levels: -5 , $-3,-2,-1,-0.5,-0.1,0,0.1,0.5,1,2,3,5 \mathrm{~m} \mathrm{~s}^{-1}$. Hatched areas (marked by thick black contours) show $95 \%$ statistical significance.

dient in the lowermost stratosphere. In addition, there is a significant warming between 40 and $50 \mathrm{~km}$ in the NH polar region due to an intensification of the polar vortex which leads in turn to the increase of air descent and adiabatic warming of the upper stratosphere.

\subsubsection{Zonal wind profile}

The influence of GCRs on the monthly mean zonal wind for February shows a significant increase of up to $5 \mathrm{~m} \mathrm{~s}^{-1}$ in the $\mathrm{NH}$ polar region, peaking in the lower stratosphere and extending all the way to the ground (see lower panel in Fig. 6). The acceleration is caused by the cooling of the polar lower stratosphere due to the GCR-induced polar ozone depletion, opposed to the warming of the northern mid-latitude lowermost stratosphere. These changes increase the meridional temperature gradient, leading to acceleration of the zonal wind in agreement with the thermal wind balance. Intensification of the polar vortex leads in turn to the increase of air descent and adiabatic warming of the upper stratosphere, in turn causing deceleration of the zonal wind (Limpasuvan et al., 2005). 


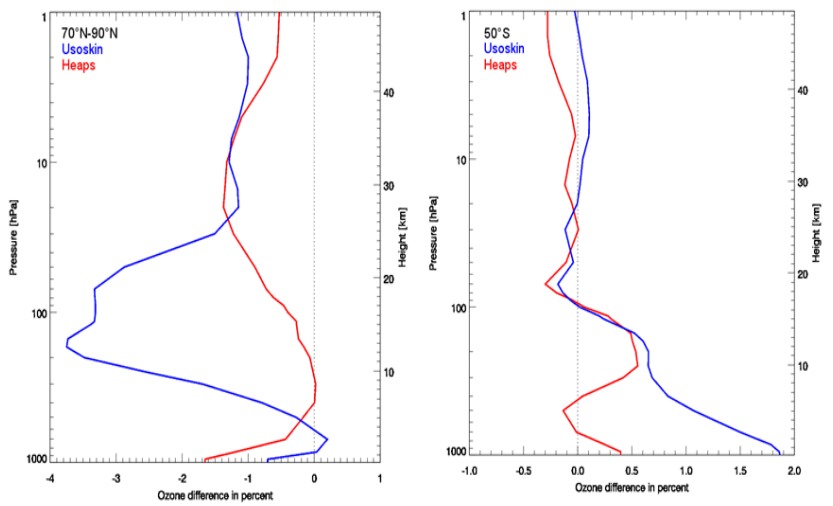

Fig. 7. GCR-induced effects on ozone, $\left(\left[\mathrm{O}_{3}\right]_{\mathrm{GCR}^{-}}\right.$ $\left.\left[\mathrm{O}_{3}\right]_{\text {control }}\right) /\left[\mathrm{O}_{3}\right]_{\text {control }}$, given in percent. Left panel shows the annual mean averaged for $70^{\circ}-90^{\circ} \mathrm{N}$ and for $50^{\circ} \mathrm{S}$ (right). Red line: parameterization by Heaps (1976). Blue line: parameterization by Usoskin et al. (2010). Results are averaged from 1978-2002 (all seasons, after allowing for a 2-year model spin-up).

\subsubsection{Comparison of the Heaps and CRII parameterizations}

As mentioned above, a major difference between the Heaps parameterization and Usoskin's model-based approach is that the ionization rate calculated with the Heaps parameterization is applicable only at altitudes above $18 \mathrm{~km}$, whereas the ionization rates derived by Usoskin extend to the ground. As described above, a proper description of the ionization rate in the upper troposphere and lower stratosphere is required for a correct simulation in of atmospheric composition, in particular of free tropospheric ozone.

The importance of the accuracy of the GCR parameterizations for ozone is illustrated in Fig. 7. The left panel represents the annual mean effect of GCRs on the zonal average ozone at $70^{\circ}-90^{\circ} \mathrm{N}$ given in percent averaged from 1978 to 2002. It reveals that the Heaps parameterization (Heaps, red line; Usoskin, blue line) clearly underestimates the ozone decrease due to the additional $\mathrm{NO}_{\mathrm{x}}$ that is produced in the UTLS region, because it neglects the ionization below $18 \mathrm{~km}$ altitude. Even though the difference is small between Usoskin and Heaps parameterization (see right panel of Fig. 7), nevertheless, it is important to use a scheme for correctly describing the GCR-induced ozone production in the southern hemispheric troposphere.

The upper panel in Fig. 8 shows the monthly mean zonal mean effect of the GCRs on ozone at $70^{\circ}-90^{\circ} \mathrm{N}$ for November and December given in percent whereas the lower panel depicts the changes for February and March. The larger and significant decrease in November at about $30 \mathrm{~km}$ with Heaps parameterization is caused through the fact that the ionization rate is larger in the middle stratosphere (see Fig. 1) and that the PSC chemistry is not important yet. This changes in February and March: the lower panel in Fig. 8 shows that
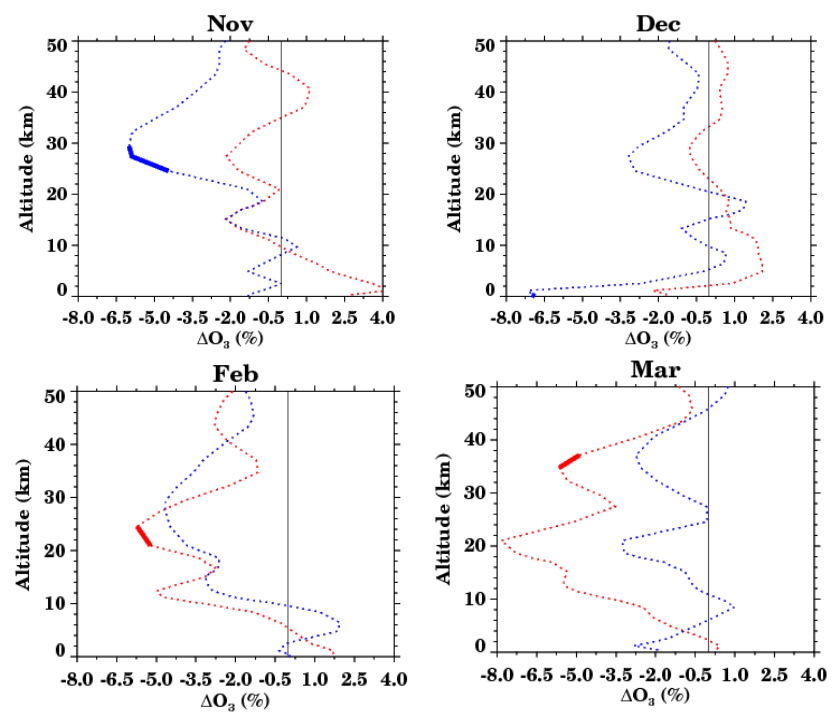

Fig. 8. GCR-induced effects on ozone, $\left(\left[\mathrm{O}_{3}\right]_{\mathrm{GCR}^{-}}\right.$ $\left.\left[\mathrm{O}_{3}\right]_{\text {control }}\right) /\left[\mathrm{O}_{3}\right]_{\text {control }}$, given in percent, for $70^{\circ}-90^{\circ} \mathrm{N}$. Upper panel: November and December; lower panel: February and March. Red lines: parameterization by Usoskin et al. (2010). Blue lines: parameterization by Heaps (1976). Thick solid lines: altitudes where the changes in ozone are significant at $95 \%$ level for the respective parameterization. Results are averaged from 1978-2002.

the parameterization with Usoskin below altitudes of $20 \mathrm{~km}$ shows a larger impact on ozone than the Heaps parameterization which stops at $18 \mathrm{~km}$.

Finally, we investigate the influence of the two GCR parameterizations on the surface air temperature (SAT) and its connection with the Arctic Oscillation. The right column of Fig. 9 shows the annual mean response, which is comparable for both parameterizations. On a monthly basis (see left column) there are clear differences. For Heaps the response is most pronounced during earlier winter (peaking in January, lower left panel in Fig. 9) and for Usoskin during late winter/spring (peaking in March, upper left panel in Fig. 9, see also Fig. 8).

The general patterns and intensities for both parameterization are in good agreement: both show a warming over the eastern part of Europe and Russia and a cooling in the high Arctic. The simulated ozone response is rather small over the $\mathrm{SH}$, therefore a smaller response of the surface air temperature can be expected. Moreover, the ocean with prescribed temperature, which dominates in the $\mathrm{SH}$, can suppress the response.

Additionally, we see that the effects of the galactic cosmic rays result in an alternating warming/cooling pattern resembling the typical response of the SAT caused by an intensification of the polar vortex known as positive phase of Arctic Oscillation (Thompson and Wallace, 1998), termed $\mathrm{AO}^{+}$. Concerning Wallace and Thompson (2002), the Northern 


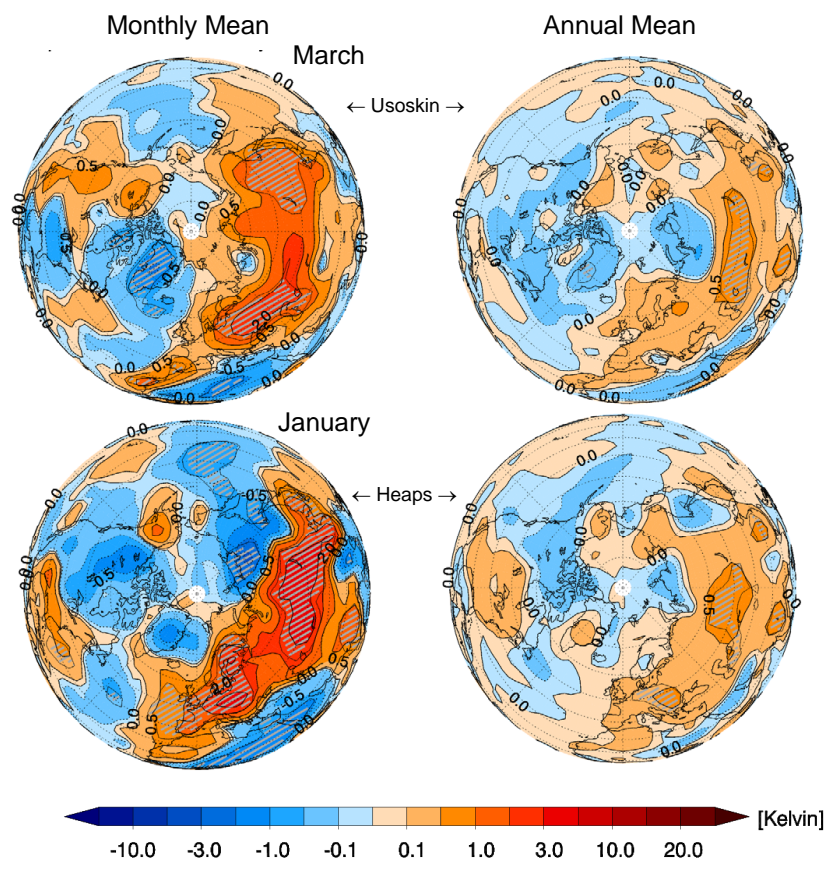

Fig. 9. Effect of GCRs on SAT, $[\mathrm{SAT}]_{\mathrm{GCR}}-[\mathrm{SAT}]_{\text {control }}$, given in Kelvin for monthly means (left) and annual mean (right). Upper panels: using ionization rate modeled by Usoskin et al. (2010). Lower panels: using parameterization by Heaps (1978). Results are averaged from 1978-2002 (after allowing for a 2-year model spin-up). Reddish colors: positive changes. Bluish colors: negative changes. Hatched areas (enclosed by thick solid contours) indicate changes with at least $95 \%$ statistical significance.

Annular Mode (NAM) and the AO are both the same. Therefore, the results presented in this paper and the papers from Seppälä et al. (2009) and Baumgärtner et al. (2010) give the same interpretation (modulation of NAM/AO through energetic particles) for the changes in the surface air temperature. A resulting interesting question is whether this response is primarily due to GCR-induced stratospheric changes or due to the penetration of the GCRs into the troposphere.

The presence of the $\mathrm{AO}^{+}$-like warming-cooling pattern also for the Heaps parameterization, which ignores GCR-effects below $18 \mathrm{~km}$, corroborates the interpretation of Thompson and Wallace (1998), namely "that under certain conditions, dynamical processes at stratospheric levels can affect the strength of the polar vortex all the way down to the earth's surface...".

\section{Summary}

Based on the 3-D CCM SOCOL v2.0 and on CRAC:CRII (the "Cosmic Ray induced Cascade: Application for Cosmic Ray Induced Ionization") model, we present in this paper a modeling study of the influence of the galactic cosmic rays on atmospheric composition, winds and temperature from $0.01 \mathrm{hPa}$ or approximately $80 \mathrm{~km}$ down to the ground.

Our calculations indicate that GCR-induced ionization leads to the following modifications in atmospheric composition, winds $(U)$, atmospheric temperatures $(T)$ and surface air temperatures (SAT). Only results with $95 \%$ level of statistical significance are given:

Southern hemispheric troposphere, pristine conditions:

- $\mathrm{NO}_{\mathrm{x}}$ : increases by more than $20 \%$ in the polar region,

- $\mathrm{HO}_{\mathrm{x}}$ : decreases of $\sim 3 \%$ in the mid-latitude upper troposphere,

- $\mathrm{HNO}_{3}$ : increases by more than $10 \%$ between the South Pole and subtropics,

- $\mathrm{O}_{3}$ : increases by up to $\sim 3 \%$ throughout the troposphere to $20 \mathrm{~km}$ between the South Pole to $20^{\circ} \mathrm{N}$,

- SAT: small patches of (significant) warming up to $0.5 \mathrm{~K}$ in Antarctica.

Northern hemispheric troposphere, anthropogenically preconditioned:

- $\mathrm{HNO}_{3}$ : marginally significant increases in the midlatitude upper troposphere,

$-\mathrm{O}_{3}$ : marginally significant decreases in the polar upper troposphere,

- $U$ : enhancements of the polar night jet by up to $5 \mathrm{~m} \mathrm{~s}^{-1}$ at the tropopause with perturbations reaching all the way to the ground,

- SAT: warming by up to $2.25 \mathrm{~K}$ in the eastern part of Europe and Russia and decreases by almost $2 \mathrm{~K}$ over Greenland.

Southern hemispheric stratosphere:

- $\mathrm{NO}_{\mathrm{x}}$ : increases by up to $4 \%$ in the tropical middle stratosphere,

- $\mathrm{HO}_{\mathrm{x}}$ : decreases by up to $3 \%$ caused by $\mathrm{OH}+\mathrm{NO}_{2}$ producing $\mathrm{HNO}_{3}$ in the low latitude lower stratosphere,

- $\mathrm{HNO}_{3}$ : largely mirroring the $\mathrm{HO}_{\mathrm{x}}$ changes, with increases by $4 \%$ in the low latitude lower stratosphere,

Northern hemispheric stratosphere:

- $\mathrm{NO}_{\mathrm{x}}$ : increases by up to $4 \%$ in the tropical middle stratosphere,

- $\mathrm{HO}_{\mathrm{x}}$ and $\mathrm{HNO}_{3}$ : similar to Southern Hemisphere, 
- $\mathrm{O}_{3}$ : strong loss in the polar lower stratosphere with annual mean mixing ratios decreasing by $3 \%$ due to additional chlorine activation (specifically in February decreases up to $5 \%$, corresponding to a loss of $>60 \mathrm{ppbv}$ ),

- $T$ : cooling by up to $-1.5 \mathrm{~K}$ in the lower polar stratosphere, opposed to a slight warming $(<+0.5 \mathrm{~K})$ in the tropical lower stratosphere and a moderate warming $(<+1.5 \mathrm{~K})$ in the upper polar stratosphere,

- $U$ : enhancements of the polar night jet by up to $5 \mathrm{~m} \mathrm{~s}^{-1}$ resulting from the enhanced meridional temperature gradient in the lower stratosphere, and a decrease by $3 \mathrm{~m} \mathrm{~s}^{-1}$ in the mesosphere.

We conclude that for $\mathrm{NO}_{\mathrm{x}}$-limited regions it is important to have a parameterization for the GCRs that extent to the surface, otherwise important consequences for tropospheric ozone (Fig. 5) and for the oxidation capacity of the troposphere (Fig. 3) will be neglected. Conversely, Galactic cosmic rays appear to affect winds and temperatures in the middle and lower atmosphere in a manner that is governed by the ionization processes in the middle atmosphere alone, i.e. a detailed description of the ionization processes in the troposphere appears to be less important. The comparison between the often applied parameterization of ionization rates derived by Heaps (1978) and the state-of-the-art modeling work by Usoskin et al. (2010), which agree largely above but differ below $18 \mathrm{~km}$, reveals that changes in the surface air temperature are to first order independent of the choice of parameterization. This suggests that the changes in tropospheric meteorology depend on changes in the stratosphere, i.e. that the acceleration of the polar night jet reaches all the way down to the Earth's surface. This constitutes an example of stratosphere-troposphere coupling. Conversely, tropospheric $\mathrm{NO}_{\mathrm{x}}$ and ozone depend strongly on a correct description of the GCRs down to the lowest parts of the troposphere. The simulations with the 3-D chemistry-climate model SOCOL show that the influence of the GCRs should not be neglected in investigations of the tropospheric and stratospheric chemistry and dynamics. The results presented in this paper show that the effects of galactic cosmic rays on the atmosphere are statistically significant (referring to the Student's T-test) in large geographic regions and for a number of relevant atmospheric species.

Acknowledgements. IU and ER acknowledge useful discussions within the ISSI Team on Study of Cosmic Ray Influence upon Atmospheric Processes. ER is partially supported by the Swiss National Science Foundation under grant CRSI122130642(FUPSOL).

Edited by: F.-J. Lübken

\section{References}

Aikin, A. C.: Energetic particle-induced enhancements of stratospheric nitric acid, Geophys. Res. Lett., 21, 859-862, 1994.

Aikin, A. C.: Production of stratospheric $\mathrm{HNO} 3$ by different ionmolecule reaction mechanisms, J. Geophys. Res., 102(D11), 12921-12925, 1997.

Baumgärtner, A. J. G., Jöckel, P., Riede, H., Stiller, G., and Funke, B.: Energetic particle precipitation in ECHAM5/MESSy - Part 2: Solar proton events, Atmos. Chem. Phys., 10, doi:10.5194/acp-10-7285-2010, 7285-7302, 2010.

Bazilevskaya, G. A., Usoskin, I. G., Flückiger, E. O., Harrison, R. G., Desorgher, L., Bütikofer, R., Krainev, M. B., Makhmutov, V. S., Stozhkov, Y. I., Svirzhevskaya, A. K., Svirzhevsky, N. S., and Kovaltsov, G. A.: Cosmic Ray Induced Ion Production in the Atmosphere, Space Sci. Rev., 137, 149-173, 2008.

Desorgher, L., Flückiger, E.O., Gurtner, M., Moser, M., and Bütikofer, R.: Atmocosmics: a Geant 4 Code for Computing the Interaction of Cosmic Rays with the Earth's Atmosphere, Internat. J. Modern Phys. A, 20, 6802-6804, 2005.

Egorova, T., Rozanov, E., Zubov, V., and Karol, I. L.: Model for Investigating Ozone Trends (MEZON), Izvestiya, Atmos. Ocean. Phys., 39, 277-292, 2003.

Egorova, T., Rozanov, E., Zubov, V., Manzini, E., Schmutz, W. and Peter, T.: Chemistry-climate model SOCOL: a validation of the present-day climatology, Atmos. Chem. Phys., 5, 1557-1576, doi:10.5194/acp-8-6365-2005, 2005.

Eyring, V., Butchart, N., Waugh, D. W., Akiyoshi, H., Austin, J., Bekki, S., Bodeker, G. E., Boville, B.A., Bruehl, C., Chipperfield, M. P., Cordero, E., Dameris, M., Deushi, M., Fioletov, V. E., Frith, S. M., Garcia, R. R., Gettelman, A., Giorgetta, M. A., Grewe, V., Jourdain, L., Kinnison, D. E., Mancini, E., Manzini, E., Marchand, M., Marsh, D. R., Nagashima, T., Newman, P. A., Nielsen, J. E., Pawson, S., Pitari, G., Plummer, D.A., Rozanov, E., Schraner, M., Shepherd, T. G., Shibata, K., Stolarski, R. S., Struthers, H., Tian, W., and Yoshiki, M.: Assessment of temperature, trace species, and ozone in chemistry-climate model simulations of the recent past, J. Geophys. Res., 111, D22308, doi:10.1029/2006JD007327, 2006.

Eyring, V., Waugh, D. W., Bodeker, G. E., Cordero, E., Akiyoshi, H., Austin, J., Beagley, S. R., Boville, B. A., Braesicke, P., Bruehl, C., Butchart, N., Chipperfield, M. P., Dameris, M., Deckert, R., Deushi, M., Frith, S. M., Garcia, R. R., Gettelman, A., Giorgetta, M. A., Kinnison, D. E., Mancini, E., Manzini, E., Marsh, D. R., Matthes, S., Nagashima, T., Newman, P. A., Nielsen, J. E., Pawson, S., Pitari, G., Plummer, D.A., Rozanov, E., Schraner, M., Scinocca, J. F., Semeniuk, K., Shepherd, T. G., Shibata, K., Steil, B., Stolarski, R. S., Tian, W., and Yoshiki, M.: Multimodel projections of stratospheric ozone in the 21st century, J. Geophys. Res., 112, D16303, doi:10.1029/2006JD008332, 2007.

Heaps, M. G.: Parametrization of the cosmic ray ion-pair production rate above $18 \mathrm{~km}$, Planet. Space Sci., 26, 513-517, 1978.

Jackman, C. H., Frederick, J. E. and Stolarski, R. S.: Production of Odd Nitrogen in the Stratosphere and Mesosphere: An intercomparison of source strengths, J. Geophys. Res., 85(C12), 7495-7505, 1980.

Kawa, S. R., Kumer, J. B., Douglass, A. R., Roche, A. E., Smith, S. E., Taylor, F. W., and Allen, D. J.: Missing chemistry of reactive nitrogen in the upper stratospheric polar winter, Geophys. Res. 
Lett., 22, 2629-2632, 1995.

Krivolutsky, A., Bazilevskaya, G., Vyushkova, T., and Knyazeva, G.: Influence of cosmic rays on chemical composition of the atmosphere: data analysis and photochemical modeling, Phys. Chem. Earth, 27, 471-476, 2002.

Limpasuvan, V., Hartmann, D. L., Thompson, D. L. H., Jeev, K., and Yung, Y. L.: Stratosphere-troposphere evolution during polar vortex intensification, J. Geophys. Res., 110, D24101, doi:10.1029/2005JD006305, 2005.

Manzini, E., McFarlane, N. A., and McLandress, C.: Impact of the Doppler spread parameterization on the simulation of the middle atmosphere circulation using the MA/ECHAM4 general circulation model, J. Geophys. Res. Atmos., 102(D22), 25751-25762, 1997.

Morgenstern, O., Akiyoshi, H., Bekki, S., Braesicke, P., Butchart, N., Chipperfield, M. P., Cugnet, D., Deushi, M., Dhomse, S. S., Garcia, R. R., Gettelman, A., Gillett, N. P., Hardiman, S. C., Jumelet, J., Kinnison, D. E., Lamarque, J.-F., Lott, F., Marchand, M., Michou, M., Nakamura, T., Olivié, D., Peter, T., Plummer, D., Pyle, J. A., Rozanov, E., Saint-Martin, D., Scinocca, J. F., Shibata, K., Sigmond, M., Smale, D., Teyssedre, H., Tian, W., Voldoire, A., and Yamashita, Y.: Anthropogenic forcing of the Northern Annular Mode in CCMVal-2 models, J. Geophys. Res., 115, D00M03, doi:10.1029/2009JD013347, 2010.

Nicolet, M.: On the production of nitric oxide by cosmic rays in the mesosphere and stratosphere, Planet. Space Sci., 23, 637-649, 1975.

O'Brien, K.: Calculated Cosmic Ray Ionization in the Lower Atmosphere, J. Geophys. Res., 75(22), 4357-4359, 1970.

O'Brien, K.: The theory of cosmic-ray and high-energy solarparticle transport in the atmosphere, in: The Natural Radiation Environment VII, Seventh International Symposium on the Natural Radiation Environment (NRE-VII), edited by: McLaughlin, J. P., Simopoulos, S. E., and Steinhäusler, F., Elsevier, Amsterdam, The Netherlands, 29-44, 2005.

Penner, J. E., Bergmann, D. J., Walton, J. J., Kinnison, D., Prather, M. J., Rotman, D., Price, C., Pickering, K. E., and Baughcum, S. L.: An evaluation of upper troposphere $\mathrm{NO}_{\mathrm{x}}$ with two models, J. Geophys. Res., 103, 22097-22113, 1998.

Porter, H. S., Jackman, C. H. and Green, A. E. S.: Efficiencies for production of atomic nitrogen and oxygen by relativistic proton impact in air, J. Chem. Phys., 65, No. 1, 1976.

Rozanov, E. V., Zubov, V. A., Schlesinger, M. E., Yang, F. and Andronova, N. G.: The UIUC three-dimensional stratospheric chemical transport model: Description and evaluation of the simulated source gases and ozone, J. Geophys. Res., 104, 1175511781, 1999.

Schmidt, H., Brasseur, G. P., Charron, M., Manzini, E., Giorgetta, M. A., Diehl, T., Fomichev, V. I., Kinnison, D., Marsh, D., and Walters, S.: The HAMMONIA Chemistry Climate Model: Sensitivity of the Mesopause Region to the 11-Year Solar Cycle and $\mathrm{CO}_{2}$ Doubling, J. Climate, 19, 3903-3931, 2006

Schraner, M., Rozanov, E., Schnadt Poberaj, C., Kenzelmann, P., Fischer, A. M., Zubov, V., Luo, B. P., Hoyle, C. R., Egorova, T., Fueglistaler, S., Brönnimann, S., Schmutz, W., and Peter, T.: Technical Note: Chemistry-climate model SOCOL: version 2.0 with improved transport and chemistry/microphysics schemes, Atmos. Chem. Phys., 8, 5957-5974, doi:10.5194/acp-8-59572008, 2008.
Seppälä, A., Verronen, P. T., Clilverd, M. A., Randall, C. E., Tamminen, J., Sofieva, J. Backman, L., and Kyrölä, E.: Arctic and Antarctic polar winter $\mathrm{NO}_{\mathrm{x}}$ and energetic particle precipitation in 2002-2006, Geophys. Res. Lett., 34, L12810, doi:10.1029/2007GL029733, 2007.

Seppälä, A., Randall, C. E., Clilverd, M. A., Rozanov, E., and Rodger, C. J.: Geomagnetic activity and polar surface air temperature variability, J. Geophys. Res., 114, A10312, doi:10.1029/2008JA014029, 2009.

Shindell, D. T., Schmidt, G. A., Miller, R. L., and Rind, D.: Northern Hemisphere winter climate response to greenhouse gas, ozone, solar, and volcanic forcing, J. Geophys. Res., 106(D7), 7193-7210, 2001.

Solomon, S., Rusch, D. W., Gerard, J.-C., Reidt, G. C. and Crutzen, P. J.: The effect of particle precipitation events on the neutral and ion chemistry of the middle atmosphere: II. Odd Hydrogen, Planet. Space Sci., 29(8), 885-892, 1981.

Thompson, D. W. J. and Wallace, J. M.: The Arctic Oscillation signature in the wintertime geopotential height and temperature fields, Geophys. Res. Lett., 25(9), 1297-1300, 1998.

Wallace, J. M. and Thompson, D. W. J.: The Pacific Center of Action of the Northern Hemisphere Annular Mode: Real or Artifact, J. Clim., 2002.

Usoskin I. G., Gladysheva, O. G., and Kovaltsov, G. A.: Cosmic ray-induced ionization in the atmosphere: spatial and temporal changes, J. Atmos. Sol. Terr. Phys., 66, 1791-1796, 2004.

Usoskin, I. G., Alanko-Huotari, K., Kovaltsov, G. A., and Mursula, K.: Heliospheric modulation of cosmic rays: Monthly reconstruction for 1951-2004, J. Geophys. Res., 110, A12108, doi:10.1029/2005JA011250, 2005.

Usoskin, I. G. and Kovaltsov, G. A.: Cosmic ray induced ionization in the atmosphere: Full modeling and practical applications, J. Geophys. Res., 111, D21206, doi:10.1029/2006JD007150, 2006.

Usoskin, I. G., Desorgher, L., Velinov, P., Storini, M., Flückiger, E. O., Bütikofer, R., and Kovaltsov, G. A.: Ionization of the earth's atmosphere by solar and galactic cosmic rays, Acta Geophys., 57, 88-101, 2009.

Usoskin, I. G., Kovaltsov, G. A., and Mironova, I. A.: Cosmic ray induced ionization model CRAC:CRII: An extension to the upper atmosphere, J. Geophys. Res., 115, D10302, doi:10.1029/2009JD013142, 2010.

Verronen, P. T., Turunen, E., Ulich, Th., and Kyrölä, E.: Modelling the effects of the October 1989 solar proton event on mesospheric odd nitrogen using a detailed ion and neutral chemistry model, Ann. Geophys., 20, 1967-1976, doi:10.5194/angeo-201967-2002, 2002.

Vitt, F. M. and Jackman, C. H.: A comparison of sources of odd nitrogen production from 1974 through 1993 in the Earth's middle atmosphere as calculated using a two-dimensional model, J. Geophys. Res., 101(D3), 6729-6739, 1996.

Winkler, H., Kazeminejad, S., Sinnhuber, M., Kallenrode, M.B., and Notholt, J.: Conversion of mesospheric $\mathrm{HCl}$ into active chlorine during the solar proton event in July 2000 in the northern polar region, J. Geophys. Res., 114, D00I03, doi:10.1029/2008JD011587, 2009. 